\title{
Bronchoscopy in intubated and non-intubated intensive care unit patients with respiratory failure
}

\author{
Setu Patolia, Rania Farhat, Rajamurugan Subramaniyam \\ Pulmonary and Critical Care Medicine, Saint Louis University, School of Medicine, Saint Louis, MO, USA \\ Contributions: (I) Conception and design: S Patolia; (II) Administrative support: None; (III) Provision of study materials or patients: None; (IV) \\ Collection and assembly of data: None; (V) Data analysis and interpretation: None; (VI) Manuscript writing: All authors; (VII) Final approval of \\ manuscript: All authors. \\ Correspondence to: Setu Patolia. 3635 Vista Avenue, Saint Louis, MO 63110, USA. Email: setu.patolia@health.slu.edu.
}

\begin{abstract}
Bronchoscopy is one of the important tool for the pulmonary and critical care physicians to diagnose and treat various pulmonary conditions. It is increasingly being used by the intensivist due to its safety and portability. The utilization of bronchoscopy in the intensive care unit (ICU) has made the diagnosis and treatment of many conditions more feasible to intensivists. Sedation, topical or intravenous, usually helps better tolerate the procedure. However, the risks and benefits of bronchoscopy should be carefully considered in critically ill patients. The hypoxic patients in ICU pose a challenge as hypoxemia is one of the known complications of bronchoscopy, and this risk is exacerbated in patients with hypoxic respiratory failure. Bronchoscopy is relatively contraindicated in patients with severe hypoxemia and coagulopathy. However, bronchoscopy in hypoxic patients can have diagnostic as well as therapeutic implications. In patients with hypoxic respiratory failure, the use of non-invasive ventilation (NIV) during bronchoscopy has been shown to reduce the risk of intubation. On the other hand, bronchoscopy in mechanically ventilated patients is not contraindicated and has been widely used. Staying focused, monitoring vital signs closely, limiting the scope time in the airway, and understanding patient's physiology may help decrease risk of complications. In this review, we discuss indications, techniques, complications, and yield associated with bronchoscopy in critically ill hypoxic patients.
\end{abstract}

Keywords: Bronchoscopy; respiratory insufficiency; hypoxia

Submitted Feb 01, 2021. Accepted for publication Jun 09, 2021.

doi: $10.21037 /$ jtd-19-3709

View this article at: https://dx.doi.org/10.21037/jtd-19-3709

\section{Introduction}

Bronchoscopy is an important tool for pulmonary and critical care physicians to diagnose as well as treat various pulmonary diseases (1-3). In the intensive care unit (ICU), due to its safety and portability (3), bronchoscopy plays a significant diagnostic and therapeutic role in critically ill patients who cannot be transported to the remote imaging or diagnostic units (1). Various conditions like vocal cord dysfunction, tracheobronchomalacia, airway obstruction, foreign bodies, pneumonia, diffuse parenchymal lung disease, and lung cancer can be easily diagnosed with bronchoscopy (3). It can also help treat several conditions including airway obstruction, foreign bodies, hemoptysis, mucus plugging, and others (4-6). In general, bronchoscopy is considered a low-risk procedure in healthy patients or patients with mild, stable systemic diseases (7). However, patients with pre-existing hypoxic respiratory failure pose a unique challenge for the bronchoscopist. The possibility of worsening hypoxia and the need for escalation of care must be weighed against the benefits of the procedure. In this review, we discuss flexible bronchoscopy in patients with hypoxemic respiratory failure, particularly those treated with non-invasive and invasive mechanical ventilatory support. 


\section{Indications and contraindications}

Indications are shown in Table 1.

\section{Contraindications}

* The American Thoracic Society recommends avoiding bronchoscopy and bronchoalveolar lavage (BAL) in patients with hypoxemia that cannot be corrected (partial pressure of oxygen $\left(\mathrm{PaO}_{2}\right)<75 \mathrm{mmHg}, \mathrm{PaO}_{2} /$ fractional inspired oxygen $\left(\mathrm{FiO}_{2}\right)<150$ or oxygen saturation $\left(\mathrm{SpO}_{2}\right)<90 \%$ with supplemental oxygen) (9).

* Transbronchial biopsy should be avoided if the patient has severe thrombocytopenia with platelet count $<50 \mathrm{~K}$, coagulation disorder, or severe renal dysfunction (3).

* NIV should be avoided if the patient has one of the following: Facial deformity, upper gastrointestinal bleeding, upper airway obstruction, inability to protect the airway, significantly altered mental status, acute coronary syndromes, severe hemodynamic instability, and respiratory or cardiac arrest (10).

\section{Preparation}

\section{Consent}

Verbal and written information explaining indications, procedure, and potential complications should be provided. If the patient does not have capacity to make decisions, next of kin should be approached to obtain informed consent. In the elective bronchoscopy, solid/fatty food should be avoided for 8 hours and light/non fatty food and nonhuman milk should be avoided for 6 hours. Clear liquids like water, fruit juice without pulp are allowed up to 2 hours prior to the procedure $(11,12)$. For patients on mechanical ventilator support or patients requiring emergency bronchoscopy, aspiration of stomach content with naso/ orogastric tube just prior to the procedure may be sufficient to prevent aspiration (13).

\section{Risks and precautions}

Critically ill patients are in general at high risk for any invasive procedures, especially those with metabolic derangements or bleeding diathesis (6). Thus, all electrolyte disturbances and coagulopathies must be corrected before starting bronchoscopy (14-16). Some factors like $\mathrm{PaO}_{2}$ less than $70 \mathrm{mmHg}$ with $\mathrm{FiO}_{2}$ greater than 70 , positive end-expiratory pressure $(\mathrm{PEEP})>10 \mathrm{cmH}_{2} \mathrm{O}$, active
Table 1 Indications (2-6,8)

Diagnostic indications
Pneumonia
Bacterial, fungal or viral
Unexplained infiltrates on chest X-ray or CT chest
Suspected foreign body
Hemoptysis
Identify the site of bleeding
Post-trauma
Identify the site of tracheal injury or tracheoesophageal fistula
Burn patients
Identify the extent of the tracheobronchial burn
Airway obstruction
Identify the etiology as benign or malignant
Therapeutic indications
Removal of foreign bodies
Mucus plugging and atelectasis
Tumor debridement for airway obstruction
coagulation
Removal of foreign bodies
endeeding from central lesions by inserting
Thent

bronchospasm, recent myocardial infarction, unstable arrhythmia, increased intracranial pressure (ICP) were identified to increase the risks of complications of bronchoscopy (2). The risks and benefits of bronchoscopy should be carefully assessed in critically ill hypoxic patients.

\section{Monitoring}

Bronchoscopy has been associated with a change in lung compliance and an increase in mean arterial pressure, mean pulmonary artery pressure, and carbon dioxide $\left(\mathrm{CO}_{2}\right)$ levels (17-19). Hypoxia and tachycardia are a result of BAL in several studies, although these were clinically insignificant in most patients (20). Bronchoscopy with BAL is associated with a worsened oxygenation, with an $80-86 \%$ reduction in $\mathrm{PaO}_{2} / \mathrm{FiO}_{2}$ ratio from baseline regardless of the volume of BAL used (21). To avoid this, we routinely increase the $\mathrm{FiO}_{2}$ to $100 \%$ prior to starting the bronchoscopy. In case of 
persistent desaturation below $88 \%$, bronchoscope should be withdrawn from the airway and either $\mathrm{FiO}_{2}$ or PEEP should be increased. Patient's oxygen saturation should increase to $95 \%$ or above prior to resuming the bronchoscopy.

Like all ICU patients, those who will undergo bronchoscopy should have continuous cardiac monitoring, non-invasive or invasive blood pressure monitoring, pulse oximetry, and end-tidal $\mathrm{CO}_{2}$ monitoring (16). Setting alarms for abnormal vital signs makes resuscitation and withdrawal from the airway faster in case of complications. Drugs for sedation reversal and treatment of arrhythmias, hypotension, and seizures and equipment needed for resuscitation should be available (22). For non-intubated patients, possible need of intubation during or after the procedure should be discussed with the patient. In such cases, a bag valve mask and an endotracheal tube (ETT) should be at the bedside before starting the procedure (22). In patients with a head injury, monitoring ICP is necessary due to risk of an increase in $\mathrm{PCO}_{2}$ levels during bronchoscopy $(23,24)$.

\section{Sedation}

Patients offered sedation during bronchoscopy usually tolerate the procedure better and are less likely to have a failed procedure (25-27). If patients are already intubated prior to the procedure, then intravenous sedation should be temporarily increased to facilitate the bronchoscopy. For non-intubated hypoxic patients, physicians are usually concerned about the sedation related worsening respiratory drive and hypoxia during the procedure. In non-hypoxic patients undergoing bronchoscopy, use of moderate sedation is not associated with increased incidence of severe desaturation as compared to patients who did not receive moderate sedation (28). In a RCT by Saksitthichok et al., all patients were given $50 \mu \mathrm{g}$ of fentanyl prior to the procedure (29). Out of 51 patients studied in this RCT, no case of over sedation or desaturation requiring intubation was identified during the procedure in this trial. In an another RCT by Simon et al., authors used propofol bolus of 10 to $20 \mathrm{mg}$ every 2 to 3 minutes (30). In the noninvasive ventilation arm, out of 20 patients, none of the patients had significant desaturation or need of intubation within 8 hours after the procedure. In the high flow nasal cannula group, out of 20 patients, one patient required intubation immediately after the procedure. Rest of the patients in high flow nasal cannula group, did not require intubation within 8 hours after the procedure. Individualized approach should be used based on patient's clinical condition and duration of the procedure. Sedation with low dose fentanyl or intermittent propofol boluses are safe options.

\section{Topical anesthesia}

Lidocaine should be used for topical anesthesia during bronchoscopy, unless contraindicated (31). Both cricothyroid and spray-as-you-go techniques are effective in delivering lidocaine to the vocal cords and trachea depending upon the procedure and mode of ventilatory support (31). Nebulization can be used as a technique for delivering lidocaine to the airway (32). 1-2\% lidocaine solution should be used for spray-as-you-go administration (33). Bronchoscopists should use the lowest dose of lidocaine sufficient to prevent excessive coughing to avoid side effects like lidocaine toxicity. Average lidocaine required in most studies ranges from 80 to $160 \mathrm{mg}(34,35)$. Excess doses of lidocaine lead to central nervous system (CNS) and cardiac toxicity. The signs and symptoms of CNS toxicity ranges from periorbital numbness, nausea, confusion, drowsiness, nystagmus, paresthesia to convulsion and coma. The signs and symptoms of cardiac toxicity include hypotension, bradycardia, arrhythmia and cardiac arrest. Treatment of lidocaine toxicity is usually supportive.

\section{Bronchoscopy with non-invasive ventilation (NIV)}

NIV constitutes a cornerstone in the treatment of acute respiratory failure of various etiologies $(10,36,37)$. It reduces the intubation rate in patients with hypoxemic respiratory failure $(7,38)$. Some case series and randomized controlled studies suggested that NIV can prevent respiratory deterioration in spontaneously breathing hypoxemic patients undergoing bronchoscopy (4-6,8-10,39). NIV helps compensate for resistance and extra work of breathing created by bronchoscopy during the procedure. The use of NIV during bronchoscopy reduces the risk of intubation in patients with hypoxic respiratory failure (7). A single but well-conducted randomized trial suggests continuous positive airway pressure (CPAP) machine plus oxygen is superior to oxygen alone during bronchoscopy in patients with hypoxia, preventing the reduction in saturation and the need for ventilator support post-procedure (40). Three studies suggest NIV helps to prevent the need for mechanical ventilation in patients with hypoxia undergoing bronchoscopy $(29,30,41)$. 


\section{Procedure}

The ventilator mode should be set to pressure support (40). Inspiratory pressure should be titrated in the range from 10 to $25 \mathrm{cmH}_{2} \mathrm{O}$ and PEEP from 5 to $10 \mathrm{cmH}_{2} \mathrm{O}$ to achieve optimal ventilation and oxygenation $(30,35,41)$.

Ventilator settings should be adjusted as per the patient's tolerance. Simple full-face masks with swivel connector can be used as interfaces secured to the patient's face with elastic straps for the procedure along with bite block (Figure 1). The size of the bronchoscope used in studies ranges from 4 to $6.4 \mathrm{~mm}$ external diameter depend on the procedure intended. Both nasal and oral routes are equally safe. $2 \%$ lidocaine solution should be used for topical anesthesia of nasopharynx and tracheobronchial tree. Short term sedation can be administered and adjusted according to their respiratory and hemodynamic status $(29,30,42)$. Patients should be supplied with $100 \% \mathrm{FiO}_{2}$ during bronchoscopy (one or more of these procedures can be performed in the same bronchoscopy application: BAL, bronchoscopic brushings, biopsies, and therapeutic aspiration) under NIV. Following bronchoscopy, NIV should be continued in all patients for at least two hours to minimize the risk of intubation (43).

\section{Case scenario}

A 50-year-old male with past medical history of hypertension, diabetes mellitus and acute myeloid leukemia with history of bone marrow transplantation presented with progressive shortness of breath. He was noted to be hypoxic on room air and required $2 \mathrm{~L} / \mathrm{min}$ of oxygen via nasal cannula. CT chest showed bilateral ground glass opacities concerning for pneumonia. Despite broad spectrum antibiotics, his clinical condition continued to deteriorate and he started requiring $4 \mathrm{~L} / \mathrm{min}$ of oxygen supplementation. Decision was made to do bronchoscopy to rule out opportunistic infections. Prior to bronchoscopy, the oropharynx was anesthetized with lidocaine spray. He was placed on NIV support with IPAP of $10 \mathrm{cmH}_{2} \mathrm{O}$ and EPAP of $5 \mathrm{cmH}_{2} \mathrm{O}$. $\mathrm{FiO}_{2}$ was increased to $100 \%$. Thereafter, $50 \mathrm{mcg}$ of fentanyl IV and $1 \mathrm{mg}$ of midazolam IV was administered for moderate sedation. IPAP was titrated to maintain tidal volume of 400 and PEEP was increased to 10. After that bronchoscope was passed via the adapter, through the mask, and lidocaine was used to anesthetize vocal cord and tracheobronchial tree. A BAL was done from right middle lobe along with trans bronchial biopsies. No

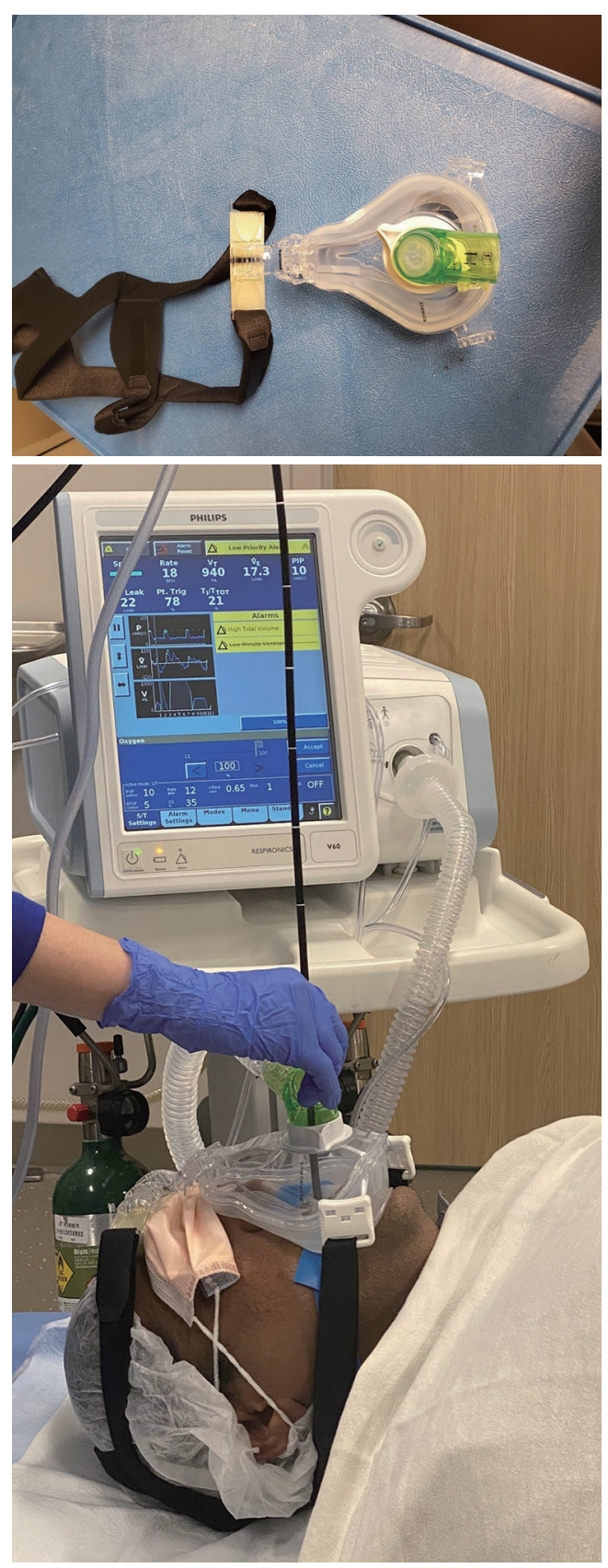

Figure 1 Non invasive ventilation mask.

significant bleeding was noted. After the bronchoscopy, patient was awake and following commands. IPAP and EPAP was weaned off along with $\mathrm{FiO}_{2}$. Patient required 6 liters of oxygen after the procedure for 24 hours to maintain oxygen saturation greater than $90 \%$. Patient was diagnosed with Mucor mycosis and started on antifungal. 

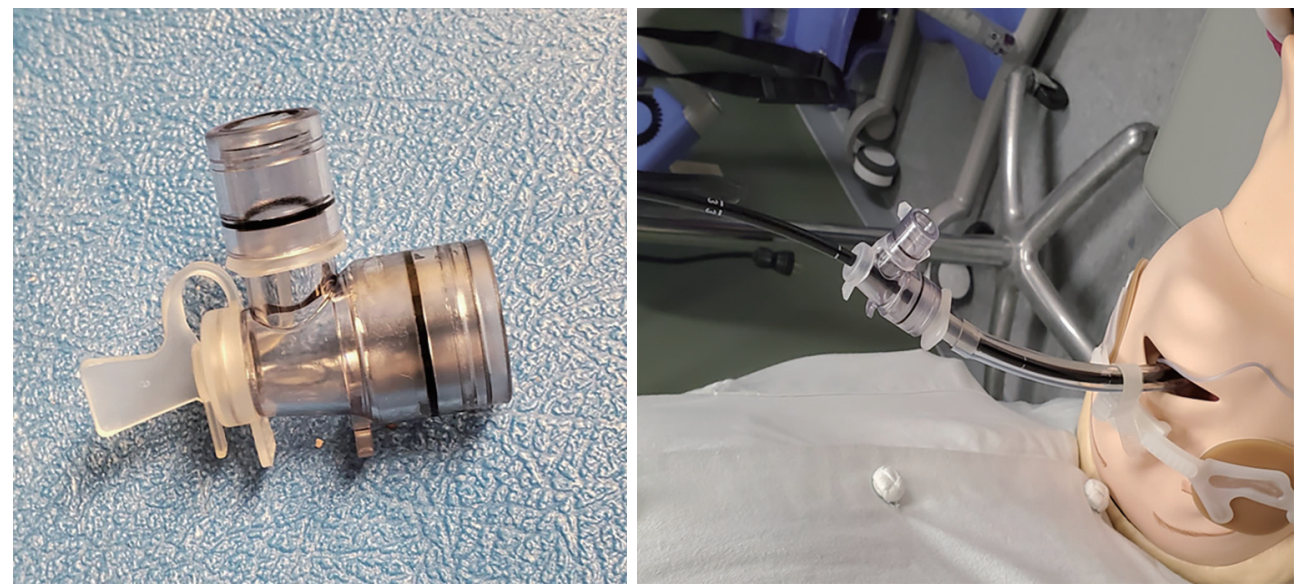

Figure 2 Swivel adaptor.

\section{Bronchoscopy in intubated patients on mechanical ventilation}

Bronchoscopy in mechanically ventilated patients is not contraindicated; on the contrary, its utility can range from determining the course of treatment (BAL and transbronchial biopsies) to being lifesaving when it is performed for the removal of mucus plugs, relieving central airway obstruction or controlling massive hemoptysis (2). Studies have reported that $65 \%$ to $79 \%$ of bronchoscopy in ICU were performed in mechanically ventilated patients $(1,2,22)$.

\section{ETT size}

The British Thoracic Society recommends that "the external diameter of a bronchoscopy used in ICU setting should be carefully selected according to the size of the ETT and the type of airway device used" (16). By introducing the bronchoscope into the ETT, it will occupy up to $66 \%$ of the diameter of ETT (16). Ideally, ET tube internal diameter should be at least $2 \mathrm{~mm}$ higher than the outer diameter of the bronchoscope. A bronchoscopy with smaller diameter won't be as effective in suctioning mucus plugs or blood clots as larger bronchoscopes; thus, the choice of the bronchoscope should also depend on the indication of bronchoscopy (2). Bronchoscopy can cause pulmonary distention and barotrauma by increasing resistance due to partial airway occlusion (44).

\section{Preparation}

A special adapter is to be attached to ETT that allows the insertion of the bronchoscope without a significant effect on tidal volume (22) (Figure 2). A bite block around the ETT can prevent any damage to the fiberoptics (2). Lubricating the bronchoscope might be needed to facilitate its entry through the ETT (2).

\section{Ventilator settings}

It is recommended to pre-oxygenate patients to $100 \% \mathrm{FiO}_{2}$ before bronchoscopy as well as during the bronchoscopy and recovery (22). The mandatory ventilatory setting is required to maintain adequate ventilation (16). Since peak pressures will increase during bronchoscopy, it is important to increase the alarm limits of pressure to ensure that adequate tidal volumes are being delivered (16). We do not recommend to use spontaneous mode of ventilation. We usually place ventilator on volume control mode of ventilation with higher pressure alarm limits. Pressure control ventilation mode can be used during the bronchoscopy. However, careful monitoring and titration of pressure is required to achieve adequate tidal volume as well as avoid the swings of tidal volume during the advancement and withdrawal of the scope. Volume targeted pressure limited ventilators can be a good mode of ventilator. But, this mode of ventilator will also require the adjustment of pressure limits to ensure adequate tidal volume. There is no 
study showing superiority of one mode of ventilation over the other mode of ventilation. $\mathrm{FiO}_{2}$ is usually set at $100 \%$ for the duration of the procedure.

\section{Complications}

\section{Hypoxemia}

Hypoxemia is one of the most common complications of bronchoscopy, which can persist up to 2 hours postprocedure (17). Transient hypoxemia can be seen in $0.8-35 \%$ of patients undergoing bronchoscopy without oxygen supplementation despite having oxygen saturation above $90 \%$ before the procedure $(45,46)$. Hypoxia could be easily corrected by oxygen supplementation. Mechanism of hypoxemia during bronchoscopy includes upper airway obstruction in obese patients, tracheobronchial obstruction with ventilation-perfusion mismatch caused by bronchoscope, suctioning, local anesthetics, bleeding, etc. as well as hypoventilation caused by sedation (47).

In healthy people, $\mathrm{PaO}_{2}$ can decline by $20-30 \mathrm{mmHg}$, whereas in the critically ill patient, it can decline up to 30 $60 \mathrm{mmHg}$ (48). It is recommended to avoid hypoxemia by oxygenating all patients with $\mathrm{FIO}_{2}$ of $100 \%$ for 15 minutes before the procedure and minimizing prolonged suctioning, which reduces forced residual capacity and tidal volume $(49,50)$. Instillation of saline and Lidocaine aggravates hypoxemia further (51). Application of NIV helps in increasing the mean airway pressure and tidal volume, thereby improving oxygenation and ventilation $(35,52,53)$.

Patients with hypoxic respiratory failure are at increased risk of developing worsening hypoxemia during bronchoscopy (54). BAL in ventilated patients transiently increases the A-a gradient and worsens the $\mathrm{PaO}_{2} / \mathrm{FiO}_{2}$ ratio independent of BAL volume $(21,55)$. This was observed mainly in acute respiratory distress syndrome (ARDS) patients, where a drop in $\mathrm{PaO}_{2}$ of more than $30 \%$ was noted in up to $35 \%$ of patients (17). Schnabel et al. (52) noted that during 164 bronchoscopies with BAL in critically ill, ventilated patients with suspected pneumonia, 29\% of patients had a decline in $\mathrm{PaO}_{2} / \mathrm{FiO}_{2}$ ratio by greater than $25 \%$ at 1 hour after the procedure and persisted in $14 \%$ patients at 24 hours after the procedure. $22 \%$ of patients developed hemodynamic instability within the first 24 hours of the procedure (52). Prebil et al. (56) studied 100 research bronchoscopies with BAL in critically ill and mechanically ventilated patients. They found that hypoxemia was the commonest complication during procedure occurring in up to $9 \%$ of patients (57). Cracco et al. (54) studied 169 bronchoscopic procedures in non-intubated patients with $\mathrm{PaO}_{2} / \mathrm{FiO}_{2}$ less than $300.35 \%$ of patients required increased ventilatory support within 24 hours, while $15 \%$ of patients required intubation (54). Kalcheim-Dekel et al. performed bronchoscopy in 7 patients with ARDS while they were in the prone position, and significant desaturation was noted in only one patient (57).

\section{Pneumothorax}

Pneumothorax is usually a rare complication during bronchoscopy with BAL. There have been some reports of pneumothorax post-BAL in ventilated patients even without transbronchial biopsies (18). In the study by Cracco et al. (54), pneumothorax rate was low. 2 patients (1.1\%) developed pneumothorax after BAL without transbronchial biopsies. Most cases of bronchoscopy associated pneumothorax are associated with transbronchial biopsies (58). O'Brien et al. (59) studied 71 mechanically ventilated patients undergoing transbronchial biopsies. Ten patients (14.3\%) developed pneumothorax after transbronchial biopsy (59). In non-lung transplant patients, pneumothorax rate was $18.9 \%$ which was higher than the rate of pneumothorax in lung transplant patients $6.5 \%(\mathrm{P}=0.085)$ (59). Pincus et al. studied 13 patients who underwent transbronchial biopsy for the diagnostic workup of diffuse pulmonary infiltrates; 2 pneumothoraxes $(15 \%)$ were noted in their study (60). Bulpa et al. (61) categorized 22 immunocompetent patients undergoing transbronchial biopsies based on the presence or absence of ARDS. Pneumothorax rate among ARDS patients was $27.2 \%$ (3/11 patients) compared to $9 \%$ ( $1 / 11$ patients) in non-ARDS patients (61). In the study by Papin et al. (62), pneumothorax was seen in 1 out of 15 patients $(6 \%)$ undergoing a transbronchial biopsy while receiving mechanical ventilation.

\section{Bleeding}

Bronchoscopy with only BAL is rarely associated with significant bleeding, even in patients with severe thrombocytopenia (63). Most of the cases of bleeding are noted with transbronchial biopsies (16). The study done by O'Brien et al. (59) showed that in mechanically ventilated patients undergoing transbronchial biopsies, clinically significant bleeding ( $>30$ and $<100 \mathrm{~mL}$ ) was observed in $4.8 \%$ of patients. Only one patient $(1.2 \%)$ had bleeding of 
Table 2 Diagnostic yield of bronchoscopy in hypoxic respiratory failure

\begin{tabular}{|c|c|c|c|}
\hline Study & Population & Intervention & Outcome \\
\hline Arcadu et al. & $\begin{array}{l}106 \text { patients with acute respiratory failure and } \\
\text { underlying ILD }\end{array}$ & $\begin{array}{l}\text { BAL. No transbronchial } \\
\text { biopsy was performed } \\
\text { in this cohort }\end{array}$ & $\begin{array}{l}\text { Diagnostic yield: } 16(13 \%) ; 12 \text { infections } \\
\text { and } 4 \text { hemorrhage }\end{array}$ \\
\hline
\end{tabular}

BAL, bronchoalveolar lavage.

more than $100 \mathrm{~mL}$ while undergoing biopsy (59). However, Bulpa et al. (61) found a higher incidence of bleeding in their study. Four out of 38 cases (10.5\%) developed significant bleeding after transbronchial biopsies. The risk of bleeding was higher in immunocompromised patients $(18.75 \%)$ as compared to immunocompetent patients (4.5\%) (61).

In general, bleeding can be seen in up to $5 \%$ of cases with transbronchial biopsy (16). However, bleeding during bronchoscopy in hypoxemic patients can worsen hypoxia and may require escalation of care or additional intervention.

\section{Mortality}

In general, mortality within 24 hours of bronchoscopy is low. Cracco et al. (54) described 4 cases of cardiac arrest $(2.3 \%)$ within 24 hours and three deaths $(1.77 \%)$ within 24 hours of bronchoscopy out of 160 bronchoscopies in mechanically ventilated patients.

\section{Diagnostic yield (Table 2)}

In the study by Cracco et al. (54), fiberoptic bronchoscopy with or without BAL provided the diagnosis in 100 (59\%) procedures, and the results led to the introduction or discontinuation of a treatment in $86(51 \%)$ procedures (54).

O'Brien et al. (59) studied 71 mechanically ventilated patients undergoing transbronchial biopsies. Out of 71 patients, 34 (47.9\%) patients were on prolonged mechanical ventilation after the lung transplant, 20 (28.2\%) patients were non-immunocompromised patients, and 17 patients (23.9\%) were immunocompromised patients (59). Transbronchial biopsy resulted in a change in medical management in 10 $(58.8 \%)$ immunocompromised patients and $12(60.0 \%)$ of the non-immunocompromised patients (59).

Bulpa et al. (61) studied 38 ventilated patients who underwent BAL and transbronchial biopsies. BAL provided a specific diagnosis in $11(29 \%)$ patients. BAL was the only positive diagnostic study in $4(10.5 \%)$ patients (61). Similarly, transbronchial biopsies provided the diagnosis in $24(63 \%)$ cases and contributed as a sole diagnostic test in $17(44 \%)$ patients (61). A combination of BAL and transbronchial biopsy provided the diagnosis in $28(74 \%)$ patients and resulted in a change in therapy in $24(63 \%)$ patients (61).

Bronchoscopy in the clinical assessment of acute respiratory failure in patients with interstitial lung disease is often performed with only a $13 \%$ yield in this large retrospective cohort (64). In one study that looked at patients who had bronchoscopy for hemoptysis, $29 \%$ of the patients had bronchogenic carcinoma, 23\% had bronchitis, and $22 \%$ no obvious cause (2). The yield of bronchoscopy in removing mucous plugs and improving aeration of the lungs ranged between $41 \%$ and $81 \%$ (2). When air was insufflated through the working channel of the bronchoscopy, the percentage of patients with re-expansion of the atelectatic lung increased to $85 \%$ (65).

\section{Conclusions}

Some patients treated for acute respiratory failure in the 
ICU will require diagnostic or therapeutic bronchoscopy. While bronchoscopy is generally considered a safe intervention (7), it is well known that bronchoscopy may induce significant hypoxemia (39). Bronchoscopy in patients with hypoxic respiratory failure carries increased risks compared to non-hypoxic patients. That is why risks and benefits should be thoroughly assessed before proceeding with bronchoscopy. Bronchoscopy may be performed with NIV or mechanical ventilation. Maneuvers like BAL are well tolerated. However, careful consideration should be taken before proceeding with transbronchial biopsies.

\section{Acknowledgments}

Funding: None.

\section{Footnote}

Provenance and Peer Review: This article was commissioned by the Guest Editors (Jonathan S. Kurman, Ashutosh Sachdeva and Rahul Nanchal) for the series "Interventional Pulmonology in the Intensive Care Unit Environment" published in Fournal of Thoracic Disease. The article has undergone external peer review.

Conflicts of Interest: All authors have completed the ICMJE uniform disclosure form (available at: http://dx.doi. org/10.21037/jtd-19-3709). The series "Interventional Pulmonology in the Intensive Care Unit Environment" was commissioned by the editorial office without any funding sponsorship. All authors have no other conflicts of interest to declare.

Ethical Statement: The authors are accountable for all aspects of the work in ensuring that questions related to the accuracy or integrity of any part of the work are appropriately investigated and resolved.

Open Access Statement: This is an Open Access article distributed in accordance with the Creative Commons Attribution-NonCommercial-NoDerivs 4.0 International License (CC BY-NC-ND 4.0), which permits the noncommercial replication and distribution of the article with the strict proviso that no changes or edits are made and the original work is properly cited (including links to both the formal publication through the relevant DOI and the license). See: https://creativecommons.org/licenses/by-nc-nd/4.0/.

\section{References}

1. Koh SO, Kim JH, Oh HK. Clinical experiences of fiberoptic bronchoscopy in patients with respiratory failure in the intensive care unit. Yonsei Med J 1990;31:219-24.

2. Raoof S, Mehrishi S, Prakash UB. Role of bronchoscopy in modern medical intensive care unit. Clin Chest Med 2001;22:241-61, vii.

3. Silver MR, Balk RA. Bronchoscopic procedures in the intensive care unit. Crit Care Clin 1995;11:97-109.

4. Ambrosino N, Guarracino F. Unusual applications of noninvasive ventilation. Eur Respir J 2011;38:440-9.

5. Korkmaz Ekren P, Basarik AB, Gurgun A, et al. Can fiberoptic bronchoscopy ne applied to critically ill patients treated with noninvasive ventilation for acute respiratory distress syndrome? Prospective observational study. BMC Pulm Med 2016;16:89.

6. Confalonieri M, Potena A, Carbone G, et al. Acute respiratory failure in patients with severe communityacquired pneumonia. A prospective randomized evaluation of noninvasive ventilation. Am J Respir Crit Care Med 1999;160:1585-91.

7. Depuydt PO, Benoit DD, Vandewoude KH, et al. Outcome in noninvasively and invasively ventilated hematologic patients with acute respiratory failure. Chest 2004;126:1299-306.

8. Rittayamai N, Brochard L. Recent advances in mechanical ventilation in patients with acute respiratory distress syndrome. Eur Respir Rev 2015;24:132-40.

9. Goldstein RA, Rohatgi PK, Bergofsky EH, et al. Clinical role of bronchoalveolar lavage in adults with pulmonary disease. Am Rev Respir Dis 1990;142:481-6.

10. Nava $S$, Hill N. Non-invasive ventilation in acute respiratory failure. Lancet 2009;374:250-9.

11. Practice Guidelines for Preoperative Fasting and the Use of Pharmacologic Agents to Reduce the Risk of Pulmonary Aspiration: Application to Healthy Patients Undergoing Elective Procedures: An Updated Report by the American Society of Anesthesiologists Task Force on Preoperative Fasting and the Use of Pharmacologic Agents to Reduce the Risk of Pulmonary Aspiration. Anesthesiology 2017;126:376-93.

12. Dobson G, Chow L, Filteau L, et al. Guidelines to the Practice of Anesthesia - Revised Edition 2020. Can J Anaesth 2020;67:64-99.

13. Lee JC, Williams GW, Kozar RA, et al. Multitargeted Feeding Strategies Improve Nutrition Outcome and Are Associated With Reduced Pneumonia in a Level 1 Trauma 
Intensive Care Unit. JPEN J Parenter Enteral Nutr 2018;42:529-37.

14. Kozak EA, Brath LK. Do "screening" coagulation tests predict bleeding in patients undergoing fiberoptic bronchoscopy with biopsy? Chest 1994;106:703-5.

15. Brickey DA, Lawlor DP. Transbronchial biopsy in the presence of profound elevation of the international normalized ratio. Chest 1999;115:1667-71.

16. Du Rand IA, Blaikley J, Booton R, et al. British Thoracic Society guideline for diagnostic flexible bronchoscopy in adults: accredited by NICE. Thorax 2013;68 Suppl 1:11-i44.

17. Trouillet JL, Guiguet M, Gibert C, et al. Fiberoptic bronchoscopy in ventilated patients. Evaluation of cardiopulmoclininary risk under midazolam sedation. Chest 1990;97:927-33.

18. Steinberg KP, Mitchell DR, Maunder RJ, et al. Safety of bronchoalveolar lavage in patients with adult respiratory distress syndrome. Am Rev Respir Dis 1993;148:556-61.

19. Klein U, Karzai W, Zimmermann P, et al. Changes in pulmonary mechanics after fiberoptic bronchoalveolar lavage in mechanically ventilated patients. Intensive Care Med 1998;24:1289-93.

20. Markou NK, Kanakaki MC, Boutzouka E, et al. Fluctuations in gas exchange andcardiovascular parameters during flexible bronchoscopy. J Bronchol 1999;6:241-6.

21. Bauer TT, Torres A, Ewig S, et al. Effects of bronchoalveolar lavage volume on arterial oxygenation in mechanically ventilated patients with pneumonia. Intensive Care Med 2001;27:384-93.

22. Barrett CR Jr. Flexible fiberoptic bronchoscopy in the critically ill patient. Methodology and indications. Chest 1978;73:746-9.

23. Kerwin AJ, Croce MA, Timmons SD, et al. Effects of fiberoptic bronchoscopy on intracranial pressure in patients with brain injury: a prospective clinical study. J Trauma 2000;48:878-82; discussion 882-3.

24. Peerless JR, Snow N, Likavec MJ, et al. The effect of fiberoptic bronchoscopy on cerebral hemodynamics in patients with severe head injury. Chest 1995;108:962-5.

25. Maguire GP, Rubinfeld AR, Trembath PW, et al. Patients prefer sedation for fibreoptic bronchoscopy. Respirology 1998;3:81-5.

26. Morris LG, Zeitler DM, Amin MR. Unsedated flexible fiberoptic bronchoscopy in the resident clinic: technique and patient satisfaction. Laryngoscope 2007;117:1159-62.

27. De S. Assessment of patient satisfaction and lidocaine requirement during flexible bronchoscopy without sedation. J Bronchology Interv Pulmonol 2009;16:176-9.
28. Hong KS, Choi EY, Park DA, et al. Safety and Efficacy of the Moderate Sedation During Flexible Bronchoscopic Procedure: A Systematic Review and Meta-Analysis of Randomized Controlled Trials. Medicine (Baltimore) 2015;94:e1459.

29. Saksitthichok B, Petnak T, So-Ngern A, et al. A prospective randomized comparative study of highflow nasal cannula oxygen and non-invasive ventilation in hypoxemic patients undergoing diagnostic flexible bronchoscopy. J Thorac Dis 2019;11:1929-39.

30. Simon M, Braune S, Frings D, et al. High-flow nasal cannula oxygen versus non-invasive ventilation in patients with acute hypoxaemic respiratory failure undergoing flexible bronchoscopy--a prospective randomised trial. Crit Care 2014;18:712.

31. Webb AR, Woodhead MA, Dalton HR, et al. Topical nasal anaesthesia for fibreoptic bronchoscopy: patients' preference for lignocaine gel. Thorax 1989;44:674-5.

32. Isaac PA, Barry JE, Vaughan RS, et al. A jet nebuliser for delivery of topical anesthesia to the respiratory tract. A comparison with cricothyroid puncture and direct spraying for fibreoptic bronchoscopy. Anaesthesia 1990;45:46-8.

33. Randell T, Yli-Hankala A, Valli H, et al. Topical anaesthesia of the nasal mucosa for fibreoptic airway endoscopy. Br J Anaesth 1992;68:164-7.

34. Efthimiou J, Higenbottam T, Holt D, et al. Plasma concentrations of lignocaine during fibreoptic bronchoscopy. Thorax 1982;37:68-71.

35. Antonelli M, Conti G, Riccioni L, et al. Noninvasive positive-pressure ventilation via face mask during bronchoscopy with BAL in high-risk hypoxemic patients. Chest 1996;110:724-8.

36. Schönhofer B, Kuhlen R, Neumann P, et al. Non-invasive ventilation as treatment for acute respiratory insufficiency. Essentials from the new S3 guidelines. Anaesthesist 2008;57:1091-102.

37. Kluge S, Baumann HJ, Kreymann G. Intrahospital transport of a patient with acute exacerbation of chronic obstructive pulmonary disease under noninvasive ventilation. Intensive Care Med 2005;31:886.

38. Hilbert G, Gruson D, Vargas F, et al. Noninvasive ventilation in immunosuppressed patients with pulmonary infiltrates, fever, and acute respiratory failure. N Engl J Med 2001;344:481-7.

39. Albertini RE, Harrell JH 2nd, Kurihara N, Moser KM. Arterial hypoxemia induced by fiberoptic bronchoscopy. JAMA 1974;230:1666-7.

40. Maitre B, Jaber S, Maggiore SM, et al. Continuous 
positive airway pressure during fiberoptic bronchoscopy in hypoxemic patients. A randomized double-blind study using a new device. Am J Respir Crit Care Med 2000;162:1063-7.

41. Antonelli M, Conti G, Rocco M, et al. Noninvasive positive-pressure ventilation vs. conventional oxygen supplementation in hypoxemic patients undergoing diagnostic bronchoscopy. Chest 2002;121:1149-54.

42. Clark G, Licker M, Younossian AB, et al. Titrated sedation with propofol or midazolam for flexible bronchoscopy: a randomised trial. Eur Respir J 2009;34:1277-83.

43. Esquinas A, Zuil M, Scala R, et al. Bronchoscopy during non-invasive mechanical ventilation: a review of techniques and procedures. Arch Bronconeumol 2013;49:105-12.

44. Labbe A, Meyer F, Albertini M. Bronchoscopy in intensive care units. Paediatr Respir Rev 2004;5 Suppl A:S15-9.

45. Milman N, Faurschou P, Grode G, et al. Pulse oximetry during fibreoptic bronchoscopy in local anaesthesia: frequency of hypoxaemia and effect of oxygen supplementation. Respiration 1994;61:342-7.

46. Mouchantaf FG, Shostak E, Lamb CR. Characteristics and financial costs of patients with respiratory failure at bronchoscopy. J Bronchology Interv Pulmonol 2012;19:188-94.

47. Chhajed PN, Glanville AR. Management of hypoxemia during flexible bronchoscopy. Clin Chest Med 2003;24:511-6.

48. Matsumoto T, Sato Y, Fukuda S, et al. Safety and efficacy of bronchoalveolar lavage using a laryngeal mask airway in cases of acute hypoxaemic respiratory failure with diffuse lung infiltrates. Intern Med 2015;54:731-5.

49. Herrejón A, Simó M, Pérez ME, et al. Comparación de la presión arterialy transcutánea de oxígeno durante la fibrobroncoscopia. ArchBronconeumol 1989;25:80-3.

50. Golpe R, Mateos A. Supplemental oxygen during flexible bronchoscopy. Chest 2002;121:663-4.

51. Credle WF Jr, Smiddy JF, Shea DW, et al. Fiberoptic bronchoscopy in acute respiratory failure in the adult. $\mathrm{N}$ Engl J Med 1973;288:49-50.

52. Schnabel RM, van der Velden K, Osinski A, et al. Clinical course and complications following diagnostic bronchoalveolar lavage in critically ill mechanically ventilated patients. BMC Pulm Med 2015;15:107.

53. Meduri GU, Turner RE, Abou-Shala N, et al. Noninvasive positive pressure ventilation via face mask. First-line intervention in patients with acute hypercapnic and hypoxemic respiratory failure. Chest 1996;109:179-93.
54. Cracco C, Fartoukh M, Prodanovic H, et al. Safety of performing fiberoptic bronchoscopy in critically ill hypoxemic patients with acute respiratory failure. Intensive Care Med 2013;39:45-52.

55. Hertz MI, Woodward ME, Gross CR, et al. Safety of bronchoalveolar lavage in the critically ill, mechanically ventilated patient. Crit Care Med 1991;19:1526-32.

56. Prebil SE, Andrews J, Cribbs SK, et al. Safety of research bronchoscopy in critically ill patients. J Crit Care 2014;29:961-4.

57. Kalchiem-Dekel O, Shanholtz CB, Jeudy J, et al. Feasibility, safety, and utility of bronchoscopy in patients with ARDS while in the prone position. Crit Care 2018;22:54.

58. Milman N, Munch E, Faurschou P, et al. Fiberoptic bronchoscopy in local anaesthesia. Indications, results and complications in 1323 examinations. Acta Endosc 1993;23:151-62.

59. O'Brien JD, Ettinger NA, Shevlin D, et al. Safety and yield of transbronchial biopsy in mechanically ventilated patients. Crit Care Med 1997;25:440-6.

60. Pincus PS, Kallenbach JM, Hurwitz MD, et al. Transbronchial biopsy during mechanical ventilation. Crit Care Med 1987;15:1136-9.

61. Bulpa PA, Dive AM, Mertens L, et al. Combined bronchoalveolar lavage and transbronchial lung biopsy: safety and yield in ventilated patients. Eur Respir J 2003;21:489-94.

62. Papin TA, Grum CM, Weg JG. Transbronchial biopsy during mechanical ventilation. Chest 1986;89:168-70.

63. Faiz SA, Jimenez CA, Fellman BM, et al. Incidence of Bleeding Complications With Flexible Bronchoscopy in Cancer Patients With Thrombocytopenia. J Bronchology Interv Pulmonol 2019;26:280-6.

64. Arcadu A, Moua T. Bronchoscopy assessment of acute respiratory failure in interstitial lung disease. Respirology 2017;22:352-9.

65. Tsao TC, Tsai YH, Lan RS, et al. Treatment for collapsed lung in critically ill patients. Selective intrabronchial air insufflation using the fiberoptic bronchoscope. Chest 1990;97:435-8.

Cite this article as: Patolia S, Farhat R, Subramaniyam R. Bronchoscopy in intubated and non-intubated intensive care unit patients with respiratory failure. J Thorac Dis 2021;13(8):51255134. doi: $10.21037 /$ jtd-19-3709 